\title{
FEIBA prophylaxis in a patient with haemophilia and inhibitors
}

\section{Susan Hook*}

A case study is presented illustrating the everyday challenges faced by patients with haemophilia and inhibitors and how treatment with bypassing agents or just FEIBA prophylaxis can help to control bleeding and improve functional ability.

\section{Key words: FEIBA, haemophilia, inhibitors}

The development of inhibitors to factor VIII or factor IX poses the most serious and challenging complication in the treatment of haemophilia. Inhibitors are a major cause of morbidity and mortality [1]. In patients with inhibitors refractory to replacement therapy, bleeding is usually treated with bypassing agents such as Factor Eight Inhibitor Bypassing Activity (FEIBA, Baxter) or activated recombinant factor VII (NovoSeven, Novo Nordisk).

Prophylaxis for severe haemophilia patients without inhibitors reduces bleeding episodes and is considered the standard of care [1]. Haemophilia A and B patients with inhibitors may also benefit from prophylactic therapy. Studies have shown that prophylaxis with FEIBA or NovoSeven reduces bleeding episodes [2-6] and improves health-related quality of life (HRQoL) [7-9].

The following case study illustrates how FEIBA prophylaxis has helped one young patient to control his bleeding and improve his functional ability. It is that of a 14-year-old boy with severe haemophilia A (Factor VIII $<0.01 \mathrm{IU} / \mathrm{ml}$ ) complicated by low von Willebrand levels (vWRicof: $0.40 \mathrm{lU} / \mathrm{ml}$ and vWAg $0.31 \mathrm{lU} / \mathrm{ml}$ ). With no family history, he was diagnosed at just 11 months after presenting with bruising. In February 2002, at the age of 20 months, he developed an inhibitor (29.9 BU). He was initially treated with recombinant FVIla for bleeds and in July 2002 an attempt at immune tolerance induction (ITI) was made with recombinant factor VIII in the International ITI study. He received $200 \mathrm{IU} / \mathrm{kg} /$ day, which failed in February 2004. During ITI he was treated with recombinant VIla for intercurrent bleeds.

In November 2006 there was a second attempt at ITI, which involved 45 months of a plasma-derived product containing factor VIII and von Willebrand factor high dose $200 \mathrm{lU} / \mathrm{kg} /$ day. This too failed and was discontinued in September 2010. His inhibitor titre was 80 BU and FEIBA prophylaxis was discussed. However, his parents wanted to continue ITI as they felt that FEIBA prophylaxis would

\footnotetext{
* Susan Hook*, Advanced Haemophilia and Thrombosis Nurse Specialist, Haemophilia and Thrombosis Centre, Royal Infirmary of Edinburgh, Little France Crescent, Edinburgh EH16 4SA

Susan.Hook@anhslothian.scot.nhs.uk
}

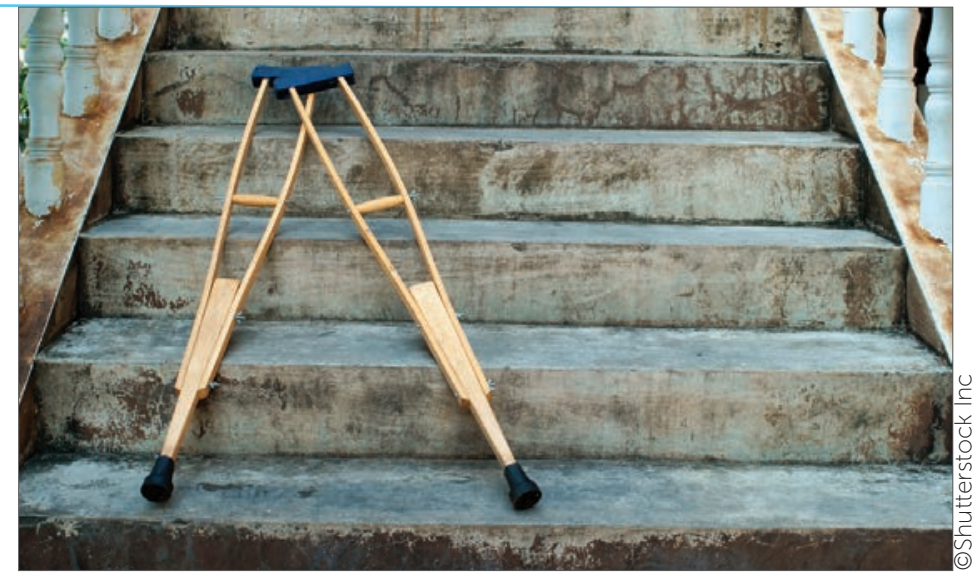

mean giving up on eradicating the inhibitor. The parents sought a second opinion from another centre. As the patient's inhibitor titre was then $350 \mathrm{BU}$, rituximab was not advised, and FEIBA prophylaxis was again proposed. This time the parents agreed, and treatment commenced in October 2010 at $50 \mathrm{IU} / \mathrm{kg}$ per day (daily dose $1500 \mathrm{IU}$ ). Intercurrent bleeds were treated with $50 \mathrm{lU} / \mathrm{kg}$ every 6-8 hours, to a maximum daily dose of $200 \mathrm{IU} / \mathrm{kg}$. In February 2013 , following a growth spurt of $1 \mathrm{~cm}$ per month with minimal weight gain, the dose was increased to 2000 $\mathrm{IU} / \mathrm{kg} /$ day.

After one month on FEIBA prophylaxis, both the boy and his mother felt happier. He had not experienced any joint bleeds and no longer required ankle splints, just insoles. He also had a full range of movement (ROM) in both ankles. The patient's mother felt more confident in allowing her son to engage in activity. In the event of a bleed, the family was advised to ensure initial resting to allow a clot to form. He continued to make progress and after one year had improved strength and stability. After two years, he was able to treat himself peripherally and had even attended a school trip in which he was able to engage in wet-walking, kayaking and mountain biking, although by the end of the trip he had experienced a bleed into his wrist.

\begin{tabular}{lll}
\hline TABLE 1: Treatment costs & & \\
\hline & & \\
$\begin{array}{l}\text { One year prior to FEIBA } \\
\text { Bleeds }\end{array}$ & Bleeds & Cost \\
- ITI (plasma + vWF product) & 60 & $£ 689,876$ \\
Total & & $£ 404,320$ \\
\hline & & \\
Prophylaxis and bleeds & & \\
Year 1 & 37 & $£ 564,176$ \\
Year 2 & 16 & $£ 453,865$ \\
Year 3 & 21 & $£ 634,480$ \\
\hline
\end{tabular}




\begin{tabular}{|c|c|c|c|c|}
\hline 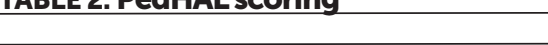 & Pre FEIBA prophylaxis & 3 years post (Mother) & 4 years post (Mother) & 4 years post (patient) \\
\hline - Lying / Sitting / Kneeling / Standing & 32 & 71.1 & 56 & 74 \\
\hline Function of the legs & 12.7 & 64 & 56.4 & 63.6 \\
\hline - Function of the arms & 63.3 & 80 & 66.7 & 73.3 \\
\hline - Use of transportation & 20 & 70 & 60 & 66.7 \\
\hline - Self-care & 55.6 & 84.4 & 64.4 & 97.8 \\
\hline - Household tasks & Not scored & 80 & 60 & 73.3 \\
\hline - Leisure activities and sports & 14.4 & 25.5 & 18.2 & 49.1 \\
\hline - Summary & 31.2 & 63.3 & 53.2 & 70.2 \\
\hline
\end{tabular}

After three years, an increase in dose was required due to growth and an increased number of bleeds. The patient's mother stated that increasing activity led to increased bleeding and therefore she limited his activity to a degree that she felt was sensible. He was able to walk up to 2 miles on occasions but mostly used a bike in the gym rather than cycling outside.

During the year prior to starting FEIBA prophylaxis, he had 60 bleeds (including 13 major bleeds), which were treated at an overall cost of $£ 689,876$. In the three years following introduction of FEIBA prophylaxis, the annual number of bleeds was substantially lower at 21 (Table 1).

The Haemophilia Activities List is a validated tool for measuring self-perceived functional ability that contains 42 multiple choice questions in seven domains [10]. The HAL has been adapted for children: the PedHAL consists of 53 items across 7 domains and is scored from 100 (no perceived difficulties) to zero $[11,12]$. The patient's PedHAL score (assessed by his mother) improved from 31.2 before prophylaxis to 53.2 after four years (Table 2). The patient's own assessments at four years were higher.

\section{Practical concerns}

While the family has been positive about prophylaxis with FEIBA, some practical difficulties have been experienced. As each infusion takes around an hour, much planning is required in order to fit it into their daily life.

A central venous access device (port) was inserted after diagnosis of the inhibitor to allow daily ITI. Over the course of 12 years, the port has been changed three times. The first port lasted 4 and half years until it was changed due skin erosion. The second was sited poorly and interfered with the use of crutches. The third was changed due to infection. The fourth and current port has been in situ for 5 years. Although both the patient and his mother have learned to infuse peripherally, both find this difficult to do each day. The patient's veins are small and the large volume to be infused often causes the vein to expel the butterfly needle.

Prophylaxis has facilitated more active physiotherapy, resulting in improved functional strength and range of movement. Prior to prophylaxis he used a wheelchair during lower limb bleeds instead of a walking aid as the latter tended to cause elbow bleeds. In the 3 years since FEIBA prophylaxis was started, he has used custom-made crutches during lower limb bleeds.

At the start of prophylaxis, he had weekly school visits for rehabilitation and monthly physiotherapy assessments as an outpatient where necessary. An exercise programme was established at school and at home, including weekly swimming with his classmates. From February 2011 he integrated into PE at school, with advice and education given to teaching staff. In March 2012, he transitioned from physiotherapy-based rehabilitation to community exercising under a Youth Referral Programme, focusing on cardiovascular fitness and general muscle strengthening.

Despite this physiotherapy regime he still continued to bleed with increased physical activity but the bleeds were less intense and he recovered quickly. Mum realised this and decided with her son to limit his activities to a degree which was deemed "safe" by them both. His comfort zone is relatively small but he is able to live comfortably within it. Sporting activities are limited to occasional gentle exercise but he enjoys and plays an active part within drama taking part in school productions. Change has been gradual. This year he spent time on the beach and was able to go on walks in the country with his family and friends when prior to prophylaxis this would not have been considered.

To the patient's mother, prophylaxis has meant that her son has been able to enjoy more activities with his peers and even their first family holiday abroad. It has resulted in reduced bleeding episodes as well as increased independence and confidence for her son. Having trust in the prophylaxis has enabled Mum to worry less as she knows he has some protection. Visits to the hospital have lessened and Mum is more relaxed about the condition.

\section{References}

1. Srivastava A, Brewer AK, Mauser-Bunschoten EP et al. Treatment Guidelines Working Group. The World Federation of Hemophilia. Guidelines for the management of hemophilia. Haemophilia 2013; 19: e1-14.

2. Hilgartner MW, Makipernaa A, DiMichele DM. Long-term FEIBA prophylaxis does not prevent progression of existing joint disease. Haemophilia 2003; 9: 261-8. 3. Valentino LA. FEIBA prophylaxis for patients with haemophilia and inhibitors. Haemophilia 2006; 12(Suppl. 5): 26-31.

4. Leissinger CA, Becton DL, Ewing NP, Valentino LA. Prophylactic treatment with activated prothrombin complex concentrate (FEIBAC) reduces the frequency of bleeding episodes in paediatric patients with haemophilia A and inhibitors. Haemophilia 2007; 13: 249-55.

5. Leissinger C, Gringeri A, Antmen B et al. Anti-inhibitor coagulant complex prophylaxis in hemophilia with inhibitors. N Engl J Med 2011; 365: 1684-92. 6. Antunes SV, Tangada S, Stasyshyn O, et al. Randomized comparison of prophylaxis and on-demand regimens with FEIBA NF in the treatment of haemophilia A and $B$ with inhibitors. Haemophilia 2014; 20: 65-72.

7. Hoots WK, Ebbesen LS, Konkle BA et al, Novoseven (F7HAEM-1505) Investigators. Secondary prophylaxis with recombinant activated factor VII improves healthrelated quality of life of haemophilia patients with inhibitors. Haemophilia 2008; 14 466-75.

8. Ekert H, Brewin T, Boey W, et al. Cost-utility analysis of recombinant factor VIla (NovoSeven) in six children with long-standing inhibitors to factor VIII or IX Haemophilia 2001; 7: 279-85.

9. Scalone L, Mantovani LG, Mannucci PM, Gringeri A, COCIS Study Investigators. Quality of life is associated to the orthopaedic status in haemophilic patients with inhibitors. Haemophilia 2006; 12: 154-62.

10. van Genderen FR, van Meeteren NL, van der Bom JG, Heijnen L, De KP, van den Berg HM, et al. Functional consequences of haemophilia in adults: the development of the Haemophilia Activities List. Haemophilia 2004; 10(5): 565-71.

11. Groen WG, van der Net J, Helders PJ, Fischer K. Development and preliminary testing of a Paediatric Version of the Haemophilia Activities List (PedHAL).

Haemophilia 2010: 16: 281-9.

12. Groen W, Van Der Net J, Lacatusu AM, Serban M, et al. Functional limitations in Romanian children with haemophilia; further testing of psychometric properties of the Paediatric Haemophilia Activities List. Haemophilia 2103; 19: e116-125. 


\section{Haemophilia \\ Nurses' \\ Association \\ 2015 Conference and AGM}

Hotel LaTour, Birmingham, 6/7 March 2015

\section{FRIDAY 6 MARCH 2015}

\begin{tabular}{ll}
\hline 12.00 & Registration and lunch \\
\hline 13.00 & $\begin{array}{l}\text { Welcome } \\
\text { - Opening remarks - Kate Khair } \\
\text { - The HNA Poem - Trish Bell }\end{array}$ \\
\hline $13.15-14.45$ & $\begin{array}{l}\text { Session 1: New Products in Haemophilia } \\
\text { Chair: Emma Franklin } \\
\text { - New products, new trials and new approaches to treatment. An interactive session led by Dr Dan Hart }\end{array}$ \\
\hline $14.45-15.15$ & Tea Break / Poster and Exhibition Viewing \\
\hline $15.15-16.15$ & $\begin{array}{l}\text { Session 2: Nurses and Research } \\
\text { Chairs: Cathy Harrison / Sarah Johns } \\
\text { - Trials and tribulations of a research nurse - Simon Fletcher/Andrew Harvey } \\
\text { - HNA Research Awards Feedback - Alpha Barrie/Melanie Wilkinson }\end{array}$ \\
\hline $16.15-17.00$ & $\begin{array}{l}\text { Session 3: Advanced, Specialist or just Confused? } \\
\text { Chairs: Anna Farrell and assorted cast }\end{array}$ \\
\hline $17.00-17.30$ & $\begin{array}{l}\text { AGM Kate Khair, HNA Chair, and Cathy Harrison, HNA Treasurer } \\
\text { Kate }\end{array}$ \\
\hline 19.00 & Conference dinner
\end{tabular}

\section{SATURDAY 7 MARCH 2015}

\begin{tabular}{ll}
\hline $9.00-10.30$ & Session 4: Snippety Bits \\
& Chairs: Cathy Harrison / April Jones \\
& - speakers, 5 minutes each \\
\hline $10.30-11.10$ & Coffee Break / poster and Exhibition Viewing \\
\hline $11.15-12.15$ & Session 5: Clinical Management \\
& Chairs: Anna Farrell / Jenna Stanley \\
& - Managing pain in people with haemophilia - TBC \\
& - Bleed or synovitis case study - David Hopper \\
& - Questions \\
\hline & Session 6: Challenges in Haemophilia Nursing \\
& Chairs: Jenna Stanley / Sarah Johns \\
& Should we monitor bone mineral density in severe haemophilia? - Anna Wells \\
& - Management of the neonate with haemophilia - Vicky Vidler \\
& Panel Discussion \\
& Awards and Wrap Up \\
\hline Chairs: Kate Khair \\
- Best Poster / Best Snippety Bit \\
- Closing Remarks - Kate Khair \\
\hline Lunch and Leave
\end{tabular}

The HNA and Haemnet would like to thank our sponsors, who have provided funding for the educational component of the programme.

\section{Baxter sobl}
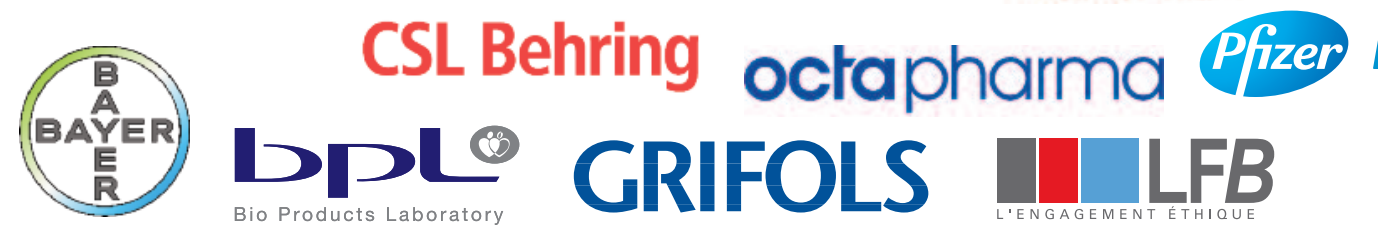

Haemophilia 